\title{
WKŁAD O. WŁADYSŁAWA SZOŁDRSKIEGO REDEMPTORYSTY (1884-1971) W DOROBEK POLSKIEJ PATRYSTYKI (W 100 rocznicę urodzin)
}

Na dziejach katolickiej monasteriologil i prezbiteriologit w Polsce wywark w ostatnich latach powazne pietno o. Włalysław Szozdrski, redemptorysta, płodny pisarz, historyk, wyuawca źródeł zaironnych, tłumacz pism Ojców Koścloła, wzorowy kapłan i zakonnik. Z okazj1 100 rocznicy urodzin pragnieny w niniejszya artykule przypomieć jogo wkład do dorobku polskioj patrystykt.

0.Władyskaw Szołdrski urodził siz w rodzinie hrabiowsisiej 22 IV $1884 \mathrm{r}$. W Kliczkowie Wielkia na terenie Zieni sicradziej ${ }^{1}$. Jego rodzican 1 byli likalysław 1 Anna z Janiaków. Líno, iz panowały jeszcze czasy polozbiorowej niewoli, społeczne środowisio rodzinne stwarzało młodemu hrabienu doskonaze warunki rozroju i formacji. Szkołe podstawowa ukoniczył w Sieradzu, gimnazjum w Kaliszu, a Seminarium Duchowno we ífockawku, glzio przebywaz w latach 1002-1906. Po świzconlach kajłaxisłich przyjotych w Płocku 28 X 1906 r. z rąk bpa Apolinarego línukowsin Grociolice k.ilotrkowa. Odezuwajtc powołanio zakonne, wstajił za zgollt swogro biskuga iv $1907 \mathrm{r}$. do 00.sedosptorystów, u którycí 1 IV 1908 r. otrzy:al w Kościstach habit zakonny, a 2 II 1909 r. złozyz śluby. W latach 1909-1921 byz misjonarzem, potem do $1925 \mathrm{r}$. profesoren historil Kosicloła w lizszym Scilnariun Ducioinya 00. Redemptorystúw w Tuciovie, a wres\%cle do r. 1939 profesoren historii w Makym

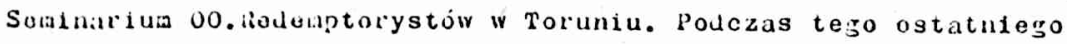
okrosu zycla, mitio iż nie odbył stuiiów stacjonarnych, złoży na untiorsylecie poznaisision egzailin kwalifikacyjny na nauczyciela histor11 w szkotach ścenich. W okresio wojny grzobywal w krakowie 1 Toruniu, edzie ratowal przed zniszczeniea 1 porcadkuirat zbiory biblio-

1 Dano blograficzno zawdzigcza: o. Marlanowi Brudziszowi, redeaptorysicie z Tuchowa, za co slikada tnu szczere podzigiowanio. 
teki Mato:so Seajna ium Duciownego. OA $1946 \mathrm{r}$. przcbywal we Wrockawiu, Gizie zwart 7 IV $1: 371$ \% Na pars dni przed swym zzonem mówit do

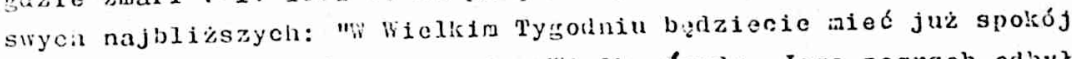
ze nunz". I rzecaywiścio, zirasł w Vilolk źsode. Jego pogrzeb odbyz sia " iielki pittek pod przewodnictwem ks. abpa Bolesława Koninka;

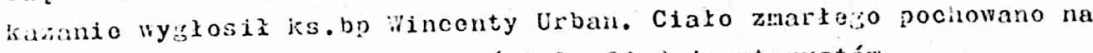
cmentiazu przy wrockawsíin kościele 0j. ledemptorystón.

0.Włalyslaw szołurski zdołal rozwinzć w swym projrante nracy kaplańskioj sywa działalność badancano-naukow k, stóra sia ujawnila na czterocil paaszczycuacis. Plerwsz? z nich była $p$ u b l $1 k$ a c $f$ a

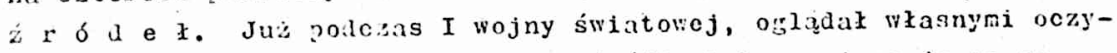
ma, jak bezmyślnie niszczono cenne íródła lub narażano je na zaglate. Z racji swef duchowej przynaleznosici, najblizsze mu okazaty sie źródła zakonne. Jeszcze podczas rojny dojrzała, w nim myśl wydania ífonumenta ilofbaueriana, z których w latach 1915-1951 opublikowano az 15 tonów. Pierwszy z nich ukazal siz wrakowle w $1915 \mathrm{r}$. pt. "Dor heilige Klamens Mopbauer und das Auswanderungspatent vom 10. Augrust 1784. Sawalung der diesbezUglichen Jocumente Miscollanea". Nastgipne tomy: II, III, IV, V, VI, VII, VIII, wydawane $\pi$ Toruniu w latacin 1929, 1930, 1931, 1932, 1933, 1934, 1936, odnosza sia do "Acta, quae ad vitam S.Clementis M.Llofbauer reforuntur". Tomy IX, $X, X I, X I I$, były drukowane w Toruniu, a XIII w Krakowie.w latach 1937, 1938, 1939 pod tytułen "Acta,quae ad vitan S.Clenentis llofbauer et ad historian Domus CSSK Redemptoris in Plotrkowice referuntur". Tou XIV I XV czyli ".lcta, quile ad vitam S.Clementis llofbauer referuntux" ujrzały światło dzicnno w izymie w 1951 roku. Sa to pr cedo wszystkin zliory wateriałór odnoszłcych sia do zycia 1 działalności biv. Kl lowensa Lofbauera.

Druga praszczyzna dziazalności natiovej 0.italyskawa Szołdrs::

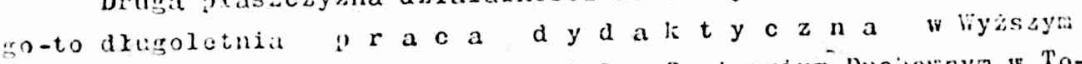
Suanariua Duchowny w Tuchow 1 e 1 :aly Seminariua Duciowny w Toruniu. Ubocznyia, a le nie malym orsocen tef dzialalnosici było przygotonanie diróch wydan /w 19251 1930/ popularnego podrq̨eznika ks.likidy. slawa Kryntckiero pt. "Dzieje Kościola pouszechnogo".

Trzocin polen dzlakania ivlelkiego ledemptorysty była p u b 11 k a c j a p r a c o tenatyce monastoriologiczno-inistorycanej. Trzoba tu wymlenić nastapujece: "Cuda 1 rask 1 Matki bosklej Inclowskiej "XVII 1 XVII wleku", Kraków 1917; "ilistorta kos- 
cioła 1 culownego obrazu Najśwlįtszej Maryi Panny w l'uchowio", Cieszyn 1920; "Vywiozienie Benoitóv z liarszawy dnia 20 czerwea 1808 roku", Włockiweck 1926; "Kościół dominikanóv i kaplica Pana Jezusa w Kośctante", Vłocławek 1927; "Zakony 1 Zgromadzenia zakonno w Polsce", Lublin 1934; "Kron1ka Benedyktynek grudzizdzkich", Polplin 1935; "ix́ontka Xx. Misjonarzy w Chełante /1697-1715/", Pelplin 1936; "Krontka Bencdyktynek Chełmlńsklch", Polplin 1937; "Swicty Wojciech w ilyranologil zactískiej", Pelplin 1949; "Swlęty Wojciech Iv logendzie 1 literaturzo", "Homo Dex" 20/1951/ 191-220; "Aliscellanea Zukorsisie", "Nasza Przeszzośćl 6/1957/ 327-377; "Z dz1ejów kultu Najświętszej Maryi Pauny w Bardo Slezskin", "Hono Dei" 28/1959/889901; 29/1960/ 121-133; "Sirięty Benon - biskup miśnteńsłs", Viarszava 1962; "Benodyktynki od nieustającoj adoracj1/Sakramentki/w Warszawio /1637-1060/", "Nasza Przeszłość"19/1964/125-118. Jest on rómnez autorom raznej pracy pośwąconej bolesnya doświadczenion narodu polskiego podczas okupacji pt. "Martyrologiun duchowieństwa poloklego w latach 1939-1945, Hzym 1968.

Czwartił wreszcle dztedzinit, w której 0.Władysław Szozdrski polozył niemało zasługi, to p a t $r$ y $s$ y k a. Szkoda, że dotychczas poza drobnyint wzmlankami ${ }^{2}$, nie poświęcono większej uwagt jego wkładow1 do polskioj patrystyk1, a jest on naprawde godny zauważonia. Wiazszośc owoców swoj pracy patrystycznej, przede wszystkin przekladow, pozostarił niestety w maszynopisach, ictóre zdeponoval w koplaci w Biblioteco Kapitulnej we Wrockawiu ${ }^{3}$. Sam zdiży w tej dzledzinio opublikować nlewiele. Trzeba tu najpierw wyntenté ogłosiona cześciant pracz/przeliład, opracowanie $i$ kouentarz/pt. "Pereginatio Aethorlao ad loca sancta/4. Dzleło to pisane $393 / 394$, odnalezione przez uczonczo włoskiego J.Gamurrinl jego w 1384, wydane no raz pler szy drukloa $81837 \mathrm{r}$., stanowi jeden "z najstar -

2 Por. o.i.jubos. SJ, Antologia Patrystyczna, Kralsór 1966, 58, 445455; tonje, Studia i tcksty patigstyczne, Kracúw 1967, 7, 193.

3 l.; 1 iane st ono do katalogu rikopisów Blblioteki Kapitulnej pod nutacia1: 752, 753, 764, 766, 763, 771, 772, 777, 733, 787, 789, $793,79:$.

4 "Luno De1" 31/1962/ 67-77, 172-179, 270-273, 363-367; 32/1963/ 251-251; 33/1961/49-55, 115-119. Tekst ton wydano późniejw catośc1 w opracowantu A.Boguck1ego w ser11 PSP 6, 160-241. 
szych opisów polróży do Zieni Swiętej". Aczkolwiek tekst jego za- . chował siz̨ "r okaleczonym rękopisie z XI w.", któremu brak początku, kolica 1 jednej karty iv środku 1 nazwiska autora, to ma ono ogromno znaczente. Uważane jest bowion za "najvazniojszy pomnik piśmiennictwa z zakresu opisów plelgrzymok do Zien1 Swiętej pierwszogo tysiz̨clocia" 5 . Jeyo polsici przekład o.A.Bober uznał za "wyborny 1 P1lologicznio wiorny" podkreślajiłc, ze oddaje on "doskonalo bezprotensjonalność stylu tego zabytku" ${ }^{6}$. Z Innych prac o.Szołdrskiego ogłoszonych drukiem jeszcze za jego źycia, to pierwszy polsict przekład dziołka św. Fulgencjusza z luspe pt. "O wierzo czyli o legulo prawdziwoj viary do Piotra"?, przekład jego kazania o sw.Szozeganio oraz tzuraczenie 6 listói św. Cypriana ${ }^{9}$.

Wśród pozostavionych w maszynopisach przekładach widnieja następujqco tytuły: św.Cyprian. Listy, frocław 1965 ( mps 286); Sw.Grzegorz Wielk1, Dialogi, Vrocław 1966/ nps 212); Sw.Grzegorz Wiolk1, Homilie na Ewangelie, ks.I, 1-20, ks.II, 20-40, Wrocław 1966 ( mps 187); Siv. Mmbroży, 0 obowi.zzkach sług Kościoła, Vrockaw 1967 (mps 191); Sw. Ambrozy, Exameron, Hrocław 1067( mps 212); Sw.Ambrozy, 0 pokucie, - tajennicach, o dobru śruerci. Paulin, sekretarz św.Ambrozego, Życio św.Ambrożogo, Wrocław 1968 ( mps 151); Sw.Ambroży, 0 dziewicach, Sulpicjusz Sewor, Pista o ́́riłtym Marcinie biskuple z Tours, Wrockaw 1968 ( mps. 149); Siv. Augustyn, 0 nauce chrześcijańskiej ksizg cztery, Siv.Ambroży, 0 ucicczco od świata, Wrocłar 1968 (inps 203); Sw.Hieronim, Diulog przeciw pelaglanow, Zymoty mnichór: "Pawła, Ifllarıona, Malchusa, 0 znakomitych mezach. Sw.Aubrozy, 0 dziowictwio, Wrocław 1969 ( mps 300); Sw.Ambrozy, Wykład ewangel11 wedzug św.Lukasza, Wrocraw 1969 ( mps 431); Sw. Augustyn, Homilie na plarwszy list św.Jana

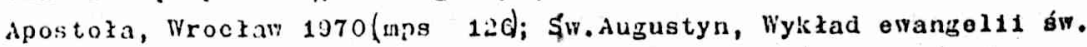
Jana, t.2: Ilomilie 34-54, /J.5-12/, hrockarv 1970/ mps 280); Sw.dugustyn, Fyiklad ewangelii św. Jana, t.3: Hom1l1e 55-124,/J.13-21/, Wrockaw 1970 ( mps 283). Wig̨ksość z nich zostaka juz opublikowana " "Pismach Starocirześcijaniskich Pisarzy" stanowi zc pierrsze podwaliny

5 W.Szołdrsk1, Porewrynacja do mlojsc śrietych z korica IV wioku, "Horio Do1" 31/1962/70.

6 A.Bobor, Antologia patrystyczna, dz.cyt. 275.

7 A.Bobor, Studia 1 toksty patrjstyczno,dz.cyt,212-245.

8 A.Bober, Antoloria patrystyczna, dz.oyt., $155-458$.

$9 \operatorname{Tan} z \theta, 59-64$. 
tivorzonia sił tej seril, inne zaś czokajly jeszeze na ogracowanie 1 opublikowanic.

W osobio zmarłego przed 14 laty o.ilfadyszama Szołdrsiciego odszodł od nas gorliby ksizdz i zalconntk, wierny sługa sakramentu pojednania, zwłaszcza i sanktuariur Matk1 Bozaj w Bardo Sl zskim 10 , szczerzo rozmiłowany w naukaci tcologicsnyci 1 w miar s stroich sit wiernto 1in słuzzcy. Jego wkład do skarbea kultury polskioj, szczególnto w Intoresującej nas dziedzinio patrystycznej, zasługuje na polne uznante 1 nadal czolia la opracovanie.

$$
\text { Bp Wincenty Urban - IYroołai }
$$

DE OPERIJUS STUDISQQUE PATRISTICIS L.SZULDiSKI CSSR /1384-1971/ /Suinelariun/

Iloc in articulo studia patsistica conatusque sciontifici Patris Ladislai Szoldrski ex Congrogatione Sanctissimi Redemptoris provenientis atque iratislaviae anno 1971 mortui jllustianiur. 